\title{
Attitude and practice of physical activity and social problem-solving ability among university students
}

\author{
Toshimasa Sone ${ }^{1 *}$, Yousuke Kawachi ${ }^{2}$, Chihiro Abe ${ }^{3}$, Yuki Otomo ${ }^{3}$, Yul-wan Sung ${ }^{2}$ and Seiji Ogawa ${ }^{2}$
}

\begin{abstract}
Background: Effective social problem-solving abilities can contribute to decreased risk of poor mental health. In addition, physical activity has a favorable effect on mental health. These previous studies suggest that physical activity and social problem-solving ability can interact by helping to sustain mental health. The present study aimed to determine the association between attitude and practice of physical activity and social problem-solving ability among university students.

Methods: Information on physical activity and social problem-solving was collected using a self-administered questionnaire. We analyzed data from 185 students who participated in the questionnaire surveys and psychological tests. Social problem-solving as measured by the Social Problem-Solving Inventory-Revised (SPSI-R) (median score 10.85) was the dependent variable. Multiple logistic regression analysis was employed to calculate the odds ratios (ORs) and 95\% confidence intervals (Cls) for higher SPSI-R according to physical activity categories.

Results: The multiple logistic regression analysis indicated that the ORs $(95 \% \mathrm{Cl})$ in reference to participants who said they never considered exercising were 2.08 (0.69-6.93), 1.62 (0.55-5.26), 2.78 (0.86-9.77), and 6.23 (1.81-23.97) for participants who did not exercise but intended to start, tried to exercise but did not, exercised but not regularly, and exercised regularly, respectively. This finding suggested that positive linear association between physical activity and social problem-solving ability ( $p$ value for linear trend $<0.01$ ).
\end{abstract}

Conclusions: The present findings suggest that regular physical activity or intention to start physical activity may be an effective strategy to improve social problem-solving ability.

Keywords: Physical activity, Social problem-solving ability, University students, Exercise

\section{Background}

Social problem-solving ability involves the higher-level cognitive processes needed to cope appropriately with various stressful problems experienced in life $[1,2]$. It can be described as encompassing two components: problem orientation and problem-solving skills. Problem orientation refers to an individual's awareness and perception of problems, and it performs a motivational function in the problem-solving process. Problem-solving skills are effective coping techniques for dealing with a particular problematic situation. They can be divided into

\footnotetext{
* Correspondence: sone-t@umin.ac.jp

${ }^{1}$ Department of Rehabilitation, Faculty of Health Science, Tohoku Fukushi

University, 1-8-1 Kunimi, Aoba-ku, Sendai 981-8522, Japan

Full list of author information is available at the end of the article
}

four parts: (1) problem definition and formulation, (2) generation of alternative solutions, (3) decision making, and (4) solution implementation and verification [3]. Effective social problem-solving abilities can contribute to decreased risk of poor mental health, including depression [4-6]. Likewise, among university students, it has been reported that higher social problem-solving ability helps to prevent depression and psychological stress [7, 8].

People can also cope with various stresses related to social problems through the use of alternative coping techniques that regulate negative emotions. Physical activity is regarded as one of these emotion-focused coping techniques [9]. In addition, physical activity has a favorable effect on mental health $[10,11]$. There are many studies that have reported on mental health issues in 
students [12]. In addition, previous studies have reported that regular physical activity has been associated with a lower risk of poor mental health in student populations [13-16].

These previous studies suggest that physical activity and social problem-solving ability can interact by helping to sustain mental health. In addition, physical activity is known to be associated with various cognitive functions such as attention or memory [17-20]. Therefore, there could be a direct association between regular physical activity and social problem-solving.

In the present study, we aimed to determine the association between attitude and practice of physical activity and social problem-solving ability among university students. We hypothesized that engaging in regular physical activity enhances social problem-solving ability. We also sought to determine the linear association between these two characteristics.

\section{Methods}

\section{Study design and participants}

Questionnaire surveys and psychological tests were conducted between July and December 2015. The study population comprised students aged 18 years or older enrolled in Tohoku Fukushi University. We recruited 2750 first- and second-year students to participate in the study using email. A total of 186 students (6.8\%) participated in the questionnaire surveys and psychological tests. One participant who did not answer questions about physical activity was excluded, leaving 185 participants $(6.7 \%)$ for analysis. Tohoku Fukushi University has four faculties (including nine departments), in Welfare, Healthcare, Education, and Management. The mission of these faculties is to deeply inquire into the truth, develop widespread knowledge and specialized skills in their fields, and build meaningful relationships, with the ultimate aim of creating paths to the wellbeing for all mankind.

\section{Measurements}

The questionnaire requested the following information from each participant: age, sex, living situation, body weight, height, sleeping condition, dietary habits, physical activity, social activity, psychological distress, and life stressors. The printed questionnaires was administered to participant.

\section{Attitude and practice of physical activity}

Attitude and practice of physical activity was defined as "undertaking moderate physical activity such as walking, riding a bicycle, or doing household tasks while standing or walking for at least $60 \mathrm{~min}$ per day in daily life." This measure has been used in the National Health and Nutrition Survey, conducted by the Ministry of Health,
Labour and Welfare of Japan [21]. The possible responses were as follows "I do not practice physical activity, and I never think about doing so," "I do not practice physical activity, but I intend to start doing so," "I try to do physical activity, but have not done it much yet," "Yes, I practice physical activity, but not regularly," and "Yes, I practice physical activity and regularly."

\section{Social problem-solving ability}

The Social Problem-Solving Inventory-Revised (SPSI-R) is a 52-item self-report questionnaire that assesses problem-solving skills [22]. The Japanese version of the SPSI-R, which has been validated previously, uses a 50item self-report questionnaire [23, 24]. The questionnaire contains five subscales: positive problem orientation (PPO), negative problem orientation (NPO), rational problem solving (RPS) (which has four subcomponents: problem definition and formulation (PDF), generation of alternative solutions (GAS), decision making (DM), and solution implementation and verification (SIV)), impulsivity/carelessness style (ICS), and avoidance style (AS). The number of items on each subscale and a sample item are as follows: PPO, four items, e.g., "I believe I can solve a problem if I try hard enough"; NPO, 10 items, e.g., "I feel afraid when I have a problem to solve"; RPS, 20 items, e.g., "I approach problems from many angles"; ICS, 10 items, e.g., "I go with the first good idea that comes to mind"; AS, six items, e.g., "I avoid thinking about problems." Higher scores on the PPO and RPS (and its subcomponents) indicate more adaptive problem-solving capacity, whereas higher scores on the NPO, ICS, and AS reflect more a more maladaptive approach to problem solving. Each item is answered on a 5-point rating scale with anchors of 0 ("not at all true of me") and 4 ("extremely true of me"). Sato et al. indicated adequate internal consistency for the Japanese version of the SPSI-R (Cronbach's $\alpha=0.89$ ) and all subscales (Cronbach's $\alpha=0.72$ to 0.92 ). In addition, the test-retest reliability over 3 weeks for all subscales as indicated by Pearson's $r$ was indicated from 0.38 to 0.61 [23]. In this study, Cronbach's $\alpha$ ranged from 0.61 to 0.90 (SPSI-R, 0.90; PPO, 0.61; NPO, 0.88; RPS, 0.86; PDF, 0.64; GAS, 0.61; DM, 0.62; SIV, 0.77; ICS, 0.77; and AS, 0.75).

\section{Statistical analyses}

First, comparisons between physical activity categories were performed via chi-squared analysis to assess differences in characteristics.

Previous studies did not report a well-accepted cutpoint for the SPSI-R [22, 23]. Therefore, we conducted analysis of covariance using continuous variables and logistic regression analysis using median scores. 
Second, an analysis of covariance was performed to investigate the significance of differences in the SPSI-R among respondents in the various physical activity categories.

Third, we conducted logistic regression analysis to evaluate the association between attitude and practice of physical activity and social problem-solving. Social problem-solving (median score 10.85) was the dependent variable, whereas the independent variable was physical activity, which was divided into five categories: "do not exercise, and never think about doing so ("I do not practice physical activity, and I never think about doing so")," "do not exercise but intend to start ("I do not practice physical activity, but I intend to start doing so")," "try to exercise but do not ("I try to do physical activity, but have not done it much yet")," "exercise but not regularly ("Yes, I practice physical activity, but not regularly,")," and "exercise regularly ("Yes, I practice physical activity and regularly")". Multiple logistic regression analysis was performed to calculate the odds ratios (ORs) and 95\% confidence intervals (CIs) for higher social problem-solving according to these five physical activity categories. Furthermore, we repeated the logistic regression analysis after modifying the dependent variable to each subscale, including PPO, NPO, RPS (PDF, GAS, DM, and SIV taken individually), ICS, and AS. The median scores for each of these variables were as follows: PPO, 12; NPO, 23; RPS, 45; PDF, 13; GAS, 12; DM, 11; SIV, 10; ICS, 19; AS, 12.

Fourth, we estimated the $p$ value for the linear trend using the five possible responses regarding physical activity level as a continuous variable ("do not exercise, and never think about doing," "do not exercise but intend to start," "try to exercise but do not," "exercise but not regularly," and "exercise regularly").

Fifth, we also conducted stratified analyses according to differences in sex, i.e., we queried whether sex significantly interfered with the association between physical activity and social problem-solving ability. Sex, as the interaction between physical activity and social problemsolving ability, was tested through the addition of crossproduct terms to the multivariate-adjusted model.

Sixth, in a supplementary analysis, we conducted multiple Poisson regression analysis to evaluate the association between attitude and practice of physical activity and SPSI-R and subscales and to calculate the rate ratios (RRs) and 95\% CIs for higher social problem-solving according to these five physical activity categories.

We considered the following variables to be potential confounders: age in years (continuous variable), sex (men or women), and living alone (yes or no). All statistical analyses were performed using SAS version 9.4 (SAS Inc., Cary, NC, USA). We considered differences at $p<0.05$ to be statistically significant.

\section{Results}

Characteristics according to physical activity

As shown in Table 1, participants belonging to the categories of "try to exercise but do not," "exercise but not regularly," and "exercise regularly" were less likely to be women or living alone than those who said they never considered exercising. In contrast, the proportion of men and those living alone was similar with regards to those who responded that they never considered exercising, and those who did not exercise but intended to begin exercising.

\section{Differences in SPSI-R and subscales among categories of physical activity}

The mean score \pm standard deviation (SD) on the SPSI-R was $10.4 \pm 2.7$ for participants who said they never considered exercising, $10.7 \pm 2.0$ for participants who did not exercise but intended to start, $10.6 \pm 2.1$ for participants who tried to exercise but did not, $10.8 \pm 2.1$ for participants who exercised but not regularly, and $12.3 \pm 2.8$ for participants who exercised regularly. We found significant differences between the five categories of physical activity with respect to the SPSI-R, at the $p<0.01$ level. Subscale analyses showed the presence of significant differences in NPO means between the five categories of physical activity (NPO; $p=0.03$ ) (Table 2).

\section{Multivariate odds ratio and $95 \%$ confidence interval of higher SPSI-R and subscales according to physical activity} As shown in Table 3, the unadjusted analysis indicated that the ORs $(95 \% \mathrm{CI})$ in reference to participants who answered "I do not practice physical activity, and I never think about doing so" were 2.03 (0.68-6.65), 1.68 (0.58-5.34), 3.11 (1.00-10.60), and 7.00 (2.11-26.13) for participants who did not exercise but intended to start, tried to exercise but did not, exercised but not regularly, and exercised regularly, respectively ( $p$ value for linear trend $<0.01$ ). This finding remained basically unchanged, even after adjusting for age, sex, and living alone ( $p$ value for linear trend $<0.01$ ). Thus, a greater frequency of higher SPSI-R scores was found among respondents stating that they tried or intended to exercise but did not, as well as those who exercised regularly or irregularly, when compared to those who had not even considered exercising. With regard to subscales and the subcomponents of RPS, linear associations were observed between physical activity and NPO, DM, and ICS. However, there were no significant linear associations between physical activity and PPO, RPS, PDF, GAS, SIV, or AS.

We further evaluated sex difference in the association between physical activity and social problem-solving ability (Table 4). There was no significant interaction between physical activity and social problem-solving ability ( $p$ value for interaction $=0.44$ ). 
Table 1 Characteristics according to physical activity

\begin{tabular}{|c|c|c|c|c|c|c|c|}
\hline \multirow[t]{3}{*}{ Characteristic } & \multirow[t]{3}{*}{ Total } & \multicolumn{5}{|l|}{ Physical activity } & \multirow[t]{3}{*}{$P$ value } \\
\hline & & \multicolumn{3}{|l|}{ Do not exercise } & \multirow{2}{*}{$\begin{array}{l}\text { Exercise } \\
\text { but not } \\
\text { regularly }\end{array}$} & \multirow{2}{*}{$\begin{array}{l}\text { Exercise } \\
\text { regularly }\end{array}$} & \\
\hline & & $\begin{array}{l}\text { And never think } \\
\text { about doing so }\end{array}$ & But intend to start & Try to exercise & & & \\
\hline No. of subjects & 185 & 20 & 43 & 55 & 35 & 32 & \\
\hline \multicolumn{8}{|l|}{ Age in years (\%) } \\
\hline 18 & 34.6 & 30.0 & 23.3 & 34.5 & 48.6 & 37.5 & \multirow[t]{5}{*}{0.44} \\
\hline 19 & 42.2 & 50.0 & 53.5 & 38.2 & 31.4 & 40.6 & \\
\hline 20 & 18.9 & 15.0 & 16.3 & 21.8 & 17.1 & 21.9 & \\
\hline 21 & 3.2 & 5.0 & 2.3 & 5.5 & 2.9 & 0.0 & \\
\hline 22 & 1.1 & 0.0 & 4.7 & 0.0 & 0.0 & 0.0 & \\
\hline \multicolumn{8}{|l|}{ Sex (\%) } \\
\hline Men & 35.7 & 20.0 & 20.9 & 34.5 & 48.6 & 53.1 & \multirow[t]{2}{*}{0.01} \\
\hline Women & 64.3 & 80.0 & 79.1 & 65.5 & 51.4 & 46.9 & \\
\hline \multicolumn{8}{|l|}{ Living alone (\%) } \\
\hline Yes & 43.2 & 50.0 & 48.8 & 40.0 & 40.0 & 40.6 & \multirow[t]{2}{*}{0.85} \\
\hline No & 56.8 & 50.0 & 51.2 & 60.0 & 60.0 & 59.4 & \\
\hline
\end{tabular}

$P$ values were calculated using a chi-square test

Multivariate rate ratio and $95 \%$ confidence interval of higher SPSI-R and subscales according to physical activity The multiple adjusted analysis indicated that the RRs (95\% CI) in reference to participants who answered "I do not practice physical activity, and I never think about doing so" were $1.57(0.63-3.91)$, $1.36(0.55-3.36), 1.78(0.71-4.49)$, and 2.31 (0.935.74) for participants who did not exercise but intended to start, tried to exercise but did not, exercised but not regularly, and exercised regularly, respectively. Higher SPSI-R was more frequently observed among participants who exercised regularly than those who did not exercise. This linear association was marginally significant ( $p$ value for linear trend $=0.05)$. With regard to the subcomponents of RPS, linear associations were observed between physical activity and DM ( $p$ value for linear trend $=0.04)$ (Additional file 1: Table S1).

Table 2 Differences in SPSI-R and subscales among categories of physical activity

\begin{tabular}{|c|c|c|c|c|c|c|}
\hline & \multicolumn{5}{|l|}{ Physical activity } & \multirow[t]{3}{*}{$P$ value } \\
\hline & \multicolumn{3}{|l|}{ Do not exercise } & \multirow{2}{*}{$\begin{array}{l}\text { Exercise } \\
\text { but not } \\
\text { regularly }\end{array}$} & \multirow{2}{*}{$\begin{array}{l}\text { Exercise } \\
\text { regularly }\end{array}$} & \\
\hline & $\begin{array}{l}\text { And never think } \\
\text { about doing so }\end{array}$ & But intend to start & Try to exercise & & & \\
\hline No. of subjects & 20 & 43 & 55 & 35 & 32 & \\
\hline SPSI-R, mean $\pm S D$ & $10.4 \pm 2.7$ & $10.7 \pm 2.0$ & $10.6 \pm 2.1$ & $10.8 \pm 2.1$ & $12.3 \pm 2.8$ & $<0.01$ \\
\hline $\mathrm{PPO}$, mean $\pm \mathrm{SD}$ & $11.4 \pm 4.1$ & $11.6 \pm 2.8$ & $11.7 \pm 3.4$ & $10.7 \pm 3.1$ & $12.9 \pm 3.6$ & 0.11 \\
\hline $\mathrm{NPO}$, mean $\pm \mathrm{SD}$ & $23.3 \pm 6.7$ & $23.2 \pm 6.9$ & $24.0 \pm 7.2$ & $21.5 \pm 8.2$ & $18.2 \pm 10.0$ & 0.03 \\
\hline $\mathrm{RPS}$, mean $\pm \mathrm{SD}$ & $43.9 \pm 12.2$ & $44.6 \pm 8.6$ & $45.0 \pm 10.0$ & $45.2 \pm 8.4$ & $49.8 \pm 10.5$ & 0.25 \\
\hline $\mathrm{PDF}$, mean $\pm \mathrm{SD}$ & $12.1 \pm 3.2$ & $12.9 \pm 2.8$ & $12.4 \pm 2.7$ & $12.3 \pm 2.5$ & $13.4 \pm 2.9$ & 0.35 \\
\hline $\mathrm{GAS}$, mean $\pm \mathrm{SD}$ & $11.2 \pm 3.8$ & $12.0 \pm 2.9$ & $11.5 \pm 2.9$ & $12.1 \pm 2.8$ & $13.0 \pm 3.1$ & 0.29 \\
\hline $\mathrm{DM}$, mean $\pm \mathrm{SD}$ & $9.9 \pm 3.0$ & $10.5 \pm 2.9$ & $10.5 \pm 2.9$ & $11.0 \pm 2.7$ & $12.3 \pm 3.7$ & 0.08 \\
\hline $\mathrm{SIV}$, mean $\pm \mathrm{SD}$ & $10.7 \pm 4.2$ & $9.3 \pm 3.5$ & $10.6 \pm 3.7$ & $9.8 \pm 3.4$ & $11.1 \pm 3.6$ & 0.23 \\
\hline $\mathrm{ICS}$, mean $\pm \mathrm{SD}$ & $19.9 \pm 6.6$ & $19.3 \pm 5.6$ & $20.0 \pm 5.6$ & $19.3 \pm 4.4$ & $17.7 \pm 6.1$ & 0.42 \\
\hline$A S$, mean $\pm S D$ & $14.1 \pm 5.2$ & $12.7 \pm 3.7$ & $13.1 \pm 5.0$ & $12.2 \pm 4.1$ & $10.8 \pm 5.2$ & 0.06 \\
\hline
\end{tabular}

Abbreviations: $A S$ avoidance style, DM decision making, GAS generation of alternative solutions, ICS impulsivity/carelessness style, NPO negative problem orientation, PDF problem definition and formulation, PPO positive problem orientation, RPS rational problem solving, SD standard deviation, SIV solution implementation and verification, and SPSI-R Social Problem-Solving Inventory-Revised

Analysis of covariance was adjusted for age in years (continuous variable), sex (men or women), and living alone (yes or no) 
Table 3 Multivariate OR and 95\% Cl of higher SPSI-R and subscales according to physical activity

\begin{tabular}{|c|c|c|c|c|c|c|}
\hline & \multicolumn{5}{|l|}{ Physical activity } & \multirow{3}{*}{$\begin{array}{l}P \text { value } \\
\text { for linear } \\
\text { trend }\end{array}$} \\
\hline & \multicolumn{3}{|l|}{ Do not exercise } & \multirow{2}{*}{$\begin{array}{l}\text { Exercise but } \\
\text { not regularly }\end{array}$} & \multirow{2}{*}{$\begin{array}{l}\text { Exercise } \\
\text { regularly }\end{array}$} & \\
\hline & $\begin{array}{l}\text { And never think } \\
\text { about doing so }\end{array}$ & But intend to start & Try to exercise & & & \\
\hline No. of subjects & 20 & 43 & 55 & 35 & 32 & \\
\hline \multicolumn{7}{|l|}{ SPSI-R } \\
\hline No. of subjects with higher SPSI-R & 6 & 20 & 23 & 20 & 24 & \\
\hline Crude OR (95\% Cl) & 1.00 (Ref.) & $\begin{array}{l}2.03 \\
(0.68-6.65)\end{array}$ & $\begin{array}{l}1.68 \\
(0.58-5.34)\end{array}$ & $\begin{array}{l}3.11 \\
(1.00-10.60)\end{array}$ & $\begin{array}{l}7.00 \\
(2.11-26.13)\end{array}$ & $<0.01$ \\
\hline Multivariate adjusted OR (95\% CI) & 1.00 (Ref.) & $\begin{array}{l}2.08 \\
(0.69-6.93)\end{array}$ & $\begin{array}{l}1.62 \\
(0.55-5.26)\end{array}$ & $\begin{array}{l}2.78 \\
(0.86-9.77)\end{array}$ & $\begin{array}{l}6.23 \\
(1.81-23.97)\end{array}$ & $<0.01$ \\
\hline \multicolumn{7}{|l|}{ PPO } \\
\hline Multivariate adjusted OR (95\% Cl) & 1.00 (Ref.) & $\begin{array}{l}1.04 \\
(0.35-3.02)\end{array}$ & $\begin{array}{l}0.90 \\
(0.32-2.53)\end{array}$ & $\begin{array}{l}0.87 \\
(0.28-2.68)\end{array}$ & $\begin{array}{l}1.50 \\
(0.47-4.81)\end{array}$ & 0.58 \\
\hline \multicolumn{7}{|l|}{ NPO } \\
\hline Multivariate adjusted OR (95\% Cl) & 1.00 (Ref.) & $\begin{array}{l}0.74 \\
(0.22-2.28)\end{array}$ & $\begin{array}{l}0.66 \\
(0.20-1.94)\end{array}$ & $\begin{array}{l}0.42 \\
(0.12-1.34)\end{array}$ & $\begin{array}{l}0.27 \\
(0.07-0.88)\end{array}$ & 0.01 \\
\hline \multicolumn{7}{|l|}{ RPS } \\
\hline Multivariate adjusted OR (95\% Cl) & 1.00 (Ref.) & $\begin{array}{l}0.71 \\
(0.24-2.08)\end{array}$ & $\begin{array}{l}0.93 \\
(0.33-2.64)\end{array}$ & $\begin{array}{l}0.79 \\
(0.25-2.45)\end{array}$ & $\begin{array}{l}2.37 \\
(0.73-8.00)\end{array}$ & 0.10 \\
\hline \multicolumn{7}{|l|}{ PDF } \\
\hline Multivariate adjusted OR (95\% Cl) & 1.00 (Ref.) & $\begin{array}{l}1.25 \\
(0.43-3.66)\end{array}$ & $\begin{array}{l}1.18 \\
(0.42-3.33)\end{array}$ & $\begin{array}{l}0.73 \\
(0.23-2.26)\end{array}$ & $\begin{array}{l}1.83 \\
(0.57-5.97)\end{array}$ & 0.64 \\
\hline \multicolumn{7}{|l|}{ GAS } \\
\hline Multivariate adjusted OR (95\% Cl) & 1.00 (Ref.) & $\begin{array}{l}1.18 \\
(0.40-3.49)\end{array}$ & $\begin{array}{l}0.94 \\
(0.33-2.70)\end{array}$ & $\begin{array}{l}1.37 \\
(0.44-4.35)\end{array}$ & $\begin{array}{l}2.66 \\
(0.80-9.16)\end{array}$ & 0.10 \\
\hline \multicolumn{7}{|l|}{ DM } \\
\hline Multivariate adjusted OR (95\% Cl) & 1.00 (Ref.) & $\begin{array}{l}1.01 \\
(0.33-3.13)\end{array}$ & $\begin{array}{l}1.00 \\
(0.34-3.01)\end{array}$ & $\begin{array}{l}3.34 \\
(1.03-11.47)\end{array}$ & $\begin{array}{l}3.67 \\
(1.10-13.10)\end{array}$ & $<0.01$ \\
\hline \multicolumn{7}{|l|}{ SIV } \\
\hline Multivariate adjusted OR $(95 \% \mathrm{Cl})$ & 1.00 (Ref.) & $\begin{array}{l}0.46 \\
(0.15-1.34)\end{array}$ & $\begin{array}{l}0.74 \\
(0.24-2.12)\end{array}$ & $\begin{array}{l}0.82 \\
(0.25-2.59)\end{array}$ & $\begin{array}{l}1.61 \\
(0.46-5.64)\end{array}$ & 0.12 \\
\hline \multicolumn{7}{|l|}{ ICS } \\
\hline Multivariate adjusted OR $(95 \% \mathrm{Cl})$ & 1.00 (Ref.) & $\begin{array}{l}1.38 \\
(0.45-4.16)\end{array}$ & $\begin{array}{l}0.94 \\
(0.32-2.68)\end{array}$ & $\begin{array}{l}0.58 \\
(0.18-1.81)\end{array}$ & $\begin{array}{l}0.48 \\
(0.14-1.51)\end{array}$ & 0.04 \\
\hline \multicolumn{7}{|l|}{ AS } \\
\hline Multivariate adjusted OR (95\% Cl) & 1.00 (Ref.) & $\begin{array}{l}0.70 \\
(0.22-2.08)\end{array}$ & $\begin{array}{l}0.60 \\
(0.20-1.70)\end{array}$ & $\begin{array}{l}0.53 \\
(0.16-1.66)\end{array}$ & $\begin{array}{l}0.35 \\
(0.10-1.11)\end{array}$ & 0.07 \\
\hline
\end{tabular}

Abbreviations: AS avoidance style, CI confidence interval, DM decision making, GAS generation of alternative solutions, ICS impulsivity/carelessness style, NPO negative problem orientation, $O R$ odds ratio, $P D F$ problem definition and formulation, $P P O$ positive problem orientation, $R P S$ rational problem solving, SIV solution implementation and verification, and SPSI-R Social Problem-Solving Inventory-Revised

The outcomes were higher for SPSI-R, PPO, NPO, RPS, PDF, GAS, DM, SIV, ICS, and AS

Multivariate ORs were adjusted for age in years (continuous variable), sex (men or women), and living alone (yes or no)

The $p$ value for the linear trend was estimated using the five categories of physical activity as a continuous variable

\section{Discussion}

This study, conducted with Japanese university students, indicated that higher SPSI-R was more frequently observed among participants who exercised regularly, compared to those who answered "I do not practice physical activity, and I never think about doing so". In addition, we found a statistically significant, positive linear association between physical activity and social problem-solving ability.
Our study indicated that higher SPSI-R was more frequently observed among participants who exercised regularly, as compared with those who answered "I do not practice physical activity, and I never think about doing so". There have been no reports on the reasons for higher SPSI-R scores in participants who exercised regularly. However, previous studies report that exercise may influence cognitive function by increasing brain 
Table 4 Multivariate OR and 95\% Cl of higher SPSI-R according to physical activity stratified by sex

\begin{tabular}{|c|c|c|c|c|c|c|}
\hline & \multicolumn{5}{|l|}{ Physical activity } & \multirow{3}{*}{$\begin{array}{l}P \text { value } \\
\text { for interaction }\end{array}$} \\
\hline & \multicolumn{3}{|l|}{ Do not exercise } & \multirow{2}{*}{$\begin{array}{l}\text { Exercise } \\
\text { but not } \\
\text { regularly }\end{array}$} & \multirow{2}{*}{$\begin{array}{l}\text { Exercise } \\
\text { regularly }\end{array}$} & \\
\hline & $\begin{array}{l}\text { And never think } \\
\text { about doing so }\end{array}$ & But intend to start & Try to exercise & & & \\
\hline Men & & & & & & 0.44 \\
\hline No. of subjects & 4 & 9 & 19 & 17 & 17 & \\
\hline No. of subjects with higher SPSI-R & 1 & 5 & 10 & 10 & 15 & \\
\hline Crude OR (95\% Cl) & 1.00 (Ref.) & $\begin{array}{l}3.75 \\
(0.33-93.82)\end{array}$ & $\begin{array}{l}3.33 \\
(0.35-74.36)\end{array}$ & $\begin{array}{l}4.29 \\
(0.44-97.14)\end{array}$ & $\begin{array}{l}22.50 \\
(1.92-618.34)\end{array}$ & \\
\hline Multivariate adjusted OR (95\% CI) & 1.00 (Ref.) & $\begin{array}{l}3.85 \\
(0.29-107.39)\end{array}$ & $\begin{array}{l}3.13 \\
(0.32-71.85)\end{array}$ & $\begin{array}{l}3.58 \\
(0.35-83.98)\end{array}$ & $\begin{array}{l}20.60 \\
(1.68-583.23)\end{array}$ & \\
\hline \multicolumn{7}{|l|}{ Women } \\
\hline No. of subjects & 16 & 34 & 36 & 18 & 15 & \\
\hline No. of subjects with higher SPSI-R & 5 & 15 & 13 & 10 & 9 & \\
\hline Crude OR (95\% Cl) & 1.00 (Ref.) & $\begin{array}{l}1.74 \\
(0.51-6.52)\end{array}$ & $\begin{array}{l}1.24 \\
(0.36-4.67)\end{array}$ & $\begin{array}{l}2.75 \\
(0.69-11.99)\end{array}$ & $\begin{array}{l}3.30 \\
(0.78-15.54)\end{array}$ & \\
\hline Multivariate adjusted OR (95\% Cl) & 1.00 (Ref.) & $\begin{array}{l}1.54 \\
(0.44-5.91)\end{array}$ & $\begin{array}{l}1.36 \\
(0.39-5.23)\end{array}$ & $\begin{array}{l}3.22 \\
(0.79-14.62)\end{array}$ & $\begin{array}{l}3.85 \\
(0.88-18.85)\end{array}$ & \\
\hline
\end{tabular}

Abbreviations: Cl confidence interval, OR odds ratio, SPSI-R Social Problem-Solving Inventory-Revised

The outcomes were higher for SPSI-R

Multivariate ORs were adjusted for age in years (continuous variable), and living alone (yes or no)

blood flow $[25,26]$. The possibility of a direct or indirect relationship between brain blood flow and higher cognitive function would require additional psychological and neuroscientific research.

Because social problem-solving ability consists of problem orientation and problem-solving skills $[1,2]$, we attempted to conduct analyses by subscale. We found significant linear associations between physical activity and NPO, DM, and ICS. The overall positive linear association between physical activity and SPSI-R was mainly attributable to the linear associations between physical activity and these three subscale or subcomponent scores. In addition, greater frequency of higher PPO and RPS (including all subcomponents) and lesser frequency of higher NPO, ICS, and AS were observed in participants who exercised regularly than in those who had not even considered exercising. Considering the findings with respect to the definition provided by D'Zurilla et al. [27], for NPO, higher motivation for physical activity is related to a lesser tendency to view a problem as a significant threat to one's well-being, to doubt one's own personal ability to solve problems successfully, or to easily become frustrated and upset when confronted with problems. For DM, greater motivation for physical activity is related to a stronger tendency to anticipate the consequences of different solutions, judge and compare them, and then choose the most effective solution. For ICS, greater motivation for physical activity is related to a weaker tendency to act impulsively on the first idea that comes to mind; to scan alternative solutions and consequences quickly, carelessly, and unsystematically; or to monitor solution outcomes carelessly and inadequately. Overall, we found that physical activity was associated with a positive result on the SPSI-R as well as on subscales of the SPSI-R.

Overall, $17.3 \%$ of the participants in this study indicated that they exercised regularly, and another $18.9 \%$ said that they exercised but not regularly. This means that only $36.2 \%$ did at least the relatively minimal amount of exercise defined as physical activity on this questionnaire. According to another study, the proportions of Japanese men and women age 20 to 29 engaging in regular exercise were $16.3 \%$ and $16.8 \%$, respectively [28]. Because, in that Ministry of Health study, regular exercise was similarly defined as $30 \mathrm{~min}$ of physical activity at least twice a week in accordance with "Health Japan 21" [28, 29], it appears that our study participants were more likely to have regular physical activity than the average among all Japanese age 20 to 29. On the other hand, previous studies in the United States indicated that $39.1 \%$ of respondents engaged in at least moderate activity [30] and that $49.9 \%$ of students reported moderate to vigorous activity [31]. Therefore, our study participants were less likely to have a high level of physical activity than U.S. students.

The SPSI-R was developed to assess social problemsolving skills [22], and it has been translated in Spanish, Chinese, and Japanese [23, 32, 33]. Among our students, the mean on the SPSI-R was 10.9. Previous studies reported means of 12.0 [23], 11.9 [34], and 12.6 [35]. Thus, our average SPSI-R score was observed to be lower than that of students in previous studies. As our students 
were recruited from one university without random sampling, our study may demonstrate selection bias. Participants in previous studies were selected from various U.S. universities using random sampling. Therefore, further study including a large sample size or a random sample is required to generalize our findings. Moreover, although we hypothesized that regular physical activity would enhance students' social problemsolving ability, our study was cross-sectional in design. A longitudinal study is required to confirm the assumed direction of the causal association studied here.

We found a statistically significant, positive linear association between physical activity and social problemsolving ability after adjusting for sex. Because participants who exercised were less likely to be women than those who did not exercise (Table 1), we conducted stratified analyses to examine whether the association between physical activity and social problem-solving ability was dependent on sex. In consequence, we found that higher SPSI-R was more frequently observed among participants who exercised regularly, irrespective of the sex.

The present study had the following limitations. First, we considered age in years, sex, and living alone as potential confounding factors. However, because the questionnaire did not include socioeconomic status, a family history of mental disorders, and having a part-time job, we did not control for these factors. A further study controlling for these factors will be required. Second, the present study may have information bias in regards to physical activity, because our questionnaire did not include metabolic equivalents (METs) or frequency per week as indicators of physical activity. We estimated the $p$ value for the linear trend using the five possible responses regarding physical activity level as a continuous variable (the responses were: "do not exercise, and never think about doing," "do not exercise but intend to start," "try to exercise but do not," "exercise but not regularly," and "exercise regularly"). Therefore, further studies using METs or frequency per week as a proxy for the amount of physical activity undertaken will be required. Third, because the response rate was low (6.8\%), the participants may not have been representative of the source population of Tohoku Fukushi University students. Our study participants were more likely to engage in regular physical activity than average among all Japanese aged 20 to 29. Therefore, this low response rate should be considered when interpreting the study results. Moreover, a form of selection bias may have occurred wherein participants who were interested in physical activity or a healthy lifestyle may have been more likely to participate in the study.

\section{Conclusions}

This study investigated the association between attitude and practice of physical activity and social problem- solving ability among Japanese university students. We found that higher SPSI-R could be more frequently observed among participants who exercised regularly, as compared to those who answered "I do not practice physical activity, and I never think about doing so". In addition, there was a positive linear association between physical activity and higher social problem-solving ability scores. The present findings suggest that regular physical activity, or an intention to start physical activity, may function as effective strategies for improving social problem-solving ability, which may subsequently help in improving university students' levels of mental health.

\section{Additional file}

Additional file 1: Table S1. Multivariate RR and 95\% Cl of higher SPSI-R and subscales according to physical activity. (DOCX $24 \mathrm{~kb}$ )

\section{Abbreviations}

AS: Avoidance style; Cl: Confidence interval; DM: Decision making; GAS: Generation of alternative solutions; ICS: Impulsivity/carelessness style; MET: Metabolic equivalent; NPO: Negative problem orientation; OR: Odds ratio; PDF: Problem definition and formulation; PPO: Positive problem orientation; RPS: Rational problem solving; RR: Rate ratio; SD: Standard deviation; SIV: Solution implementation and verification; SPSI-R: Social Problem-Solving Inventory-Revised

\section{Acknowledgments}

This study was supported by the MEXT-Supported Program for the Strategic Research Foundation at Private Universities 2014-2018 (S1411001).

\section{Funding}

This study was supported by the MEXT-Supported Program for the Strategic Research Foundation at Private Universities 2014-2018 (S1411001).

\section{Availability of data and materials}

Please contact author for data requests.

\section{Authors' contributions}

TS participated in the design of the study, performed the statistical analysis, and wrote the first draft of the manuscript text. YK, CA, YO, and YS participated in its design, conducted research, and helped to draft the manuscript. SO participated in its design, and supervised and provided commentaries to the manuscript text. All authors read and approved the final manuscript.

\section{Competing interests}

The authors declare that they have no competing interests.

\section{Consent for publication}

Written informed consent was obtained from all participants.

Ethics approval and consent to participate

The study protocol was reviewed and approved by the Ethics Committee of Tohoku Fukushi University (RS150203). Written informed consent was obtained from all participants.

\section{Publisher's Note}

Springer Nature remains neutral with regard to jurisdictional claims in published maps and institutional affiliations.

\section{Author details}

${ }^{1}$ Department of Rehabilitation, Faculty of Health Science, Tohoku Fukushi University, 1-8-1 Kunimi, Aoba-ku, Sendai 981-8522, Japan. ${ }^{2}$ Kansei Fukushi Research Institute, Tohoku Fukushi University, Sendai, Japan. ${ }^{3}$ Department of 
Welfare Psychology, Graduate School of General Welfare, Tohoku Fukushi University, Sendai, Japan.

\section{Received: 31 October 2016 Accepted: 6 March 2017} Published online: 04 April 2017

\section{References}

1. D'Zurilla TJ, Goldfried MR. Problem solving and behavior modification. J Abnorm Psychol. 1971;78:107-26.

2. D'Zurilla TJ, Nezu AM. Social problem solving in adults. In: Kendall PC, editor. Advances in cognitive-behavioral research and therapy. 1. New York: Academic; 1982. p. 201-74

3. D'Zurilla TJ, Nezu AM. Development and preliminary evaluation of the social problem-solving inventory. Psychol Assess. 1990;2:156-63.

4. Haaga DAF, Fine JA, Terrill DR, Stewart BL, Beck AT. Social problem-solving deficits, dependency, and depressive symptoms. Cognit Ther Res. 1995;19:147-58.

5. Heppner PP, Witty TE, Dixon WA. Problem-solving appraisal and human adjustment: A review of 20 years of research using the problem solving inventory. Couns Psychol. 2004;32:344-428.

6. Marx EM, Williams JM, Claridge GC. Depression and social problem solving J Abnorm Psychol. 1992;101:78-86.

7. D'Zurilla TJ, Chang EC, Nottingham EJ 4th, Faccini L. Social problem-solving deficits and hopelessness, depression, and suicidal risk in college students and psychiatric inpatients. J Clin Psychol. 1998;54:1091-107.

8. D'Zurilla TJ, Sheedy CF. Relation between social problem-solving ability and subsequent level of psychological stress in college students. J Pers $\mathrm{Soc}$ Psychol. 1991;61:841-6.

9. Haskell WL, Blair SN. The physical activity component of health promotion in occupational settings. Public Health Rep. 1980;95:109-18.

10. Griffiths A, Kouvonen A, Pentti J, Oksanen T, Virtanen M, Salo P, Väänänen A, Kivimäki M, Vahtera J. Association of physical activity with future mental health in older, mid-life and younger women. Eur J Public Health. 2014;24:813-8.

11. Hamer M, Stamatakis E, Steptoe A. Dose-response relationship between physical activity and mental health: the Scottish Health Survey. Br J Sports Med. 2009:43:1111-4.

12. Storrie K, Ahern K, Tuckett A. A systematic review: students with mental health problems-a growing problem. Int J Nurs Pract. 2010;16:1-6.

13. Adams TB, Moore MT, Dye J. The relationship between physical activity and mental health in a national sample of college females. Women Health. 2007:45:69-85

14. Ho FK, Louie LH, Chow CB, Wong WH, Ip P. Physical activity improves mental health through resilience in Hong Kong Chinese adolescents. BMC Pediatr. 2015;15:48. doi:10.1186/s12887-015-0365-0.

15. Hoegh Poulsen P, Biering K, Andersen JH. The association between leisure time physical activity in adolescence and poor mental health in early adulthood: a prospective cohort study. BMC Public Health. 2016;16:3. doi:10.1186/s12889-015-2658-5.

16. Tyson P, Wilson K, Crone D, Brailsford R, Laws K. Physical activity and mental health in a student population. J Ment Health. 2010;19:492-9.

17. Kamijo K, Pontifex MB, O'Leary KC, Scudder MR, Wu CT, Castelli DM, Hillman $\mathrm{CH}$. The effects of an afterschool physical activity program on working memory in preadolescent children. Dev Sci. 2011;14:1046-58.

18. Lambourne $\mathrm{K}$. The relationship between working memory capacity and physical activity rates in young adults. J Sports Sci Med. 2006;5:149-53.

19. Vanhelst J, Béghin L, Duhamel A, Manios Y, Molnar D, De Henauw S, Moreno LA, Ortega FB, Sjöström M, Widhalm K, Gottrand F, Healthy Lifestyle in Europe by Nutrition in Adolescence (HELENA) Study Group. Physical activity is associated with attention capacity in adolescents. J Pediatr. 2016;168:126-31.e2

20. Sibley BA, Etnier JL. The relationship between physical activity and cognition in children: A meta-analysis. Pediatr Exerc Sci. 2003;15:243-56.

21. National Institute of Health and Nutrition. Summary Results of the National Health and Nutrition Survey Japan. http://www0.nih.go.jp/eiken/english/ research/pdf/nhns2006_outline.pdf. Accessed 20 Oct 2016

22. D'Zurilla TJ, Nezu AM, Maydeu-Olivares A. Social Problem-Solving Inventory-Revised. Technical Manual. New York: Multi-Health Systems Inc; 2002

23. Sato $H$, Takahashi $F$, Matsuo M, Sakai M, Shimada H, Chen J, Kaiya H, Sakano Y Development of the Japanese version of the Social Problem-Solving
Inventory-Revised and examination of its reliability and validity. Jap J Behav Ther. 2006:32:15-30 (in Japanese).

24. Sumi K. Relations of social problem solving with interpersonal competence in Japanese students. Psychol Rep. 2011;109:976-82.

25. Hiura M, Nariai T, Ishii K, Sakata M, Oda K, Toyohara J, Ishiwata K. Changes in cerebral blood flow during steady-state cycling exercise: a study using oxygen-15-labeled water with PET. J Cereb Blood Flow Metab. 2014;34:389-96.

26. Querido JS, Sheel AW. Regulation of cerebral blood flow during exercise. Sports Med. 2007;37:765-82.

27. D'Zurilla TJ, Nezu AM, Maydeu-Olivares A. Social problem solving: Theory and assessment. In: Chang EC, D'Zurilla TJ, Sanna L, editors. Social problem solving: Theory, research, and training. Washington, DC: American Psychological Association; 2004. p. 11-27.

28. Ministry of Health, Labour and Welfare. The National Health and Nutrition Survey in Japan. http://www.mhlw.go.jp/bunya/kenkou/eiyou/dl/h25houkoku-05.pdf. Accessed 20 Oct 2016 (in Japanese).

29. Ministry of Health, Labour and Welfare. A basic direction for comprehensive implementation of national health promotion. http:// www.mhlw.go.jp/file/06-Seisakujouhou-10900000-Kenkoukyoku/ 0000047330.pdf. Accessed 20 Oct 2016

30. Seo DC, Nehl E, Agley J, Ma SM. Relations between physical activity and behavioral and perceptual correlates among midwestern college students. J Am Coll Health. 2007;56:187-97.

31. Dinger MK, Brittain DR, Hutchinson SR. Associations between physical activity and health-related factors in a national sample of college students. J Am Coll Health. 2014:62:67-74.

32. Maydeu-Olivares A, Rodríguez-Fornells A, Gómez-Benito J, D'Zurilla TJ. Psychometric properties of the Spanish adaptation of the Social Problem-Solving Inventory-Revised (SPSI-R). Pers Individ Dif. 2000;29:699-708.

33. Siu AM, Shek DT. The Chinese version of the Social Problem-Solving Inventory: Some initial results on reliability and validity. J Clin Psychol. 2005; 61:347-60.

34. Trunzo JJ, Samter W, Morse C, McClure K, Kohn C, Volkman JE, O'Brien K. College students' use of energy drinks, social problem-solving, and academic performance. J Psychoactive Drugs. 2014;46:396-401.

35. Ranjbar M, Bayani AA, Bayani A. Social problem solving ability predicts mental health among undergraduate students. Int J Prev Med. 2013;4:1337-41.

\section{Submit your next manuscript to BioMed Central and we will help you at every step:}

- We accept pre-submission inquiries

- Our selector tool helps you to find the most relevant journal

- We provide round the clock customer support

- Convenient online submission

- Thorough peer review

- Inclusion in PubMed and all major indexing services

- Maximum visibility for your research

Submit your manuscript at www.biomedcentral.com/submit 